\title{
Alcoholic cardiomyopathy and cardiovascular events - an insight from the Liptov region
}

\author{
Kycina $\mathrm{P}^{1}$, Murin $\mathrm{J}^{2}$ \\ Liptov Hospital, Department of Internal Medicine, ICU, Liptovsky Mikulas, Slovakia. \\ peter.kycina@gmail.com
}

\begin{abstract}
Aim: This study was conducted to study the association between alcohol consumption and cardiovascular events and echocardiographical parameters in 100 consumers with the average daily dose $<120 \mathrm{~g}$ and $\geq 120 \mathrm{~g}$ of alcohol per day during a 4-year follow-up.

Methods: 100 patients/heavy alcohol consumers (on average $\geq 80 \mathrm{~g}$ daily), with no cardiovascular disease, divided into 2 groups, underwent a baseline echocardiographic and clinical evaluation and were followed-up for cardiovascular events, biochemical analysis and rhythm disorder for 4 years.

Results: Data regarding the dose and duration of alcohol consumption showed a low correlation and nonlinear character between the duration of alcohol consumption and monitored parameters. There were no differences between the groups in the echo-parameters ejection fraction EF $(p=0.43)$, in the diameter of left atrium LA $(p=0.51)$. Left chamber - LVEDD - was slightly bigger in the group with a heavier drinking pattern $(p=0.09)$. There were no differences in biochemical parameters between the groups. When comparing these two groups of consumers the percentage of diabetes mellitus $(p=0.283)$, episodes of heart failure $(p=0.308)$, atrial fibrillation $(p=0.652)$, cerebral vascular accident $(p=0.722)$ and delirium $(p=0.559)$ were not significantly different; only 2 subjects suffered from myocardial infarction during the follow-up.

Conclusion: We conclude, that no significant differences $(p<0.05)$ between the two groups of heavy alcohol consumers were observed in echo parameters, biochemical values and cardiovascular events (Tab. 4, Ref. 28). Full Text in PDF www.elis.sk.

Key words: alcoholic cardiomyopathy, echocardiography, heart failure, atrial fibrillation, delirium.
\end{abstract}

Alcohol abuse is unquestionably harmful. Compelling epidemiological evidence suggests that long lasting (strong) alcohol consumption (on average $\geq 80-100$ g per day) is associated with the risk of development of alcoholic cardiomyopathy. Alcoholic cardiomyopathy (ACMP) is a common cause of cardiomyopathies (CMP) and the most common form of the secondary CMP $(1,2)$. Phenotypically and clinically it closely resembles the idiopathic dilated cardiomyopathy (DCMP). The disorder is linked to ongoing excessive alcohol consumption and appears to be both dose-related and responsive to cessation of alcohol exposure. Alcohol exposure also increases the risk of comorbidities that can contribute to cardiovascular disease, such as hypertension, stroke, arrhythmia and also sudden cardiac death. Liptov region in Northern Slovakia is known for heavy alcohol consumption - estimated consumption 13.3 litres $/ 100 \%$ of ethanol (attributable to a higher consumption of spirits, not wine or beer) per year (3) and many of these patients frequently use healthcare system facilities for that reason. In Slovakia, the estimated consumption of alcohol is on average 10.3

${ }^{1}$ Liptov Hospital, Department of Cardiology, ICU, Liptovsky Mikulas, Slovakia, and ${ }^{2}$ University Hospital, Bratislava, Slovakia

Address for correspondence: P. Kycina, MD, Dept of Internal Medicine, ICU, Liptov Hospital, Palucanska Street 25, SK-031 01 Liptovsky Mikulas, Slovakia.

Phone: +421.44 .5563218$ litres $/ 100 \%$ of ethanol per year $(4,5)$. In our first smaller survey from 2004 (47 male consumers, 16 abstainers in the comparative group, 54 years mean age, no medical treatment, no CV disease in the past, 21 of these subjects were followed by a psychiatrist for alcohol consumption), we found out significantly different echo diameters (left ventricular end-diastolic diameter (LVEDD), ejection fraction (EF), left atrium diameter (LA), interventricular thickness (IVS) and right ventricle (RV) and also some dynamic echo parameters e.g. ventricular filling due to E/A transmitral flow, the presence of pulmonary hypertension, presence of atrial fibrillation between alcohol abusers and abstainers group (6).

\section{Aim}

Our aim was to study the association between an alcohol consumption and the cardiovascular events and echocardiographical parameters in a group of 100 patients during a 4-year follow-up. Patients were divided into two subgroups - one with consumer's daily dose $<120$ g of alcohol per day and the other with $\geq 120$ g per day.

\section{Patients and methods}

Patients -100 subjects - were characterized as follows: 1) the mean age: 52.6 years \pm 10.5 , sex: 98 males $(98 \%), 2$ females $(2 \%)$, 2) examined clinically, echocardiographically and biochemically 
during the time of enrolment - period 2007-2008 and followed up for 4 years, 3 ) alcohol abuse (on average $\geq 80 \mathrm{~g}$ per day for minimally 10 years). A daily average dose/consumption (CDD) over 80 $\mathrm{g}$ (i.e. a dose consensually regarded as being able to cause the development of alcoholic cardiomyopathy) (7) was present in all subjects. Daily dose-consumption was self-reported, in some subjects it was confirmed by a history from a family member if possible and in some patients also by a modified CAGE-questionnaire. The average duration of alcohol consumption was 28 years \pm 13 . The total life dose (TTLD) consumption was also calculated in all subjects.

We studied the history and documentation also for other (mainly $\mathrm{CV}$ ) diseases and their treatment. Physical examination was performed, also ECG and echocardiography (at baseline for the main cohort). All subjects had no pre-existing known heart disease (valvular heart disease, or CAD - coronary artery disease). Echocardiography (ECHOCG) was performed on the Siemens CV 70 equipment, in the standard transthoracic approach, in the parasternal long axis (PLAX) and in the apical four-chamber (A4C) projections. Echocardiographic parameters: left ventricular end-diastolic diameter (LVEDD in $\mathrm{mm}$ ), left ventricular ejection fraction (EF in $\%$ ), left atrial size (LA in $\mathrm{mm}$ ). Ejection fraction was calculated by the Teichholz formula (PLAX) and/or the Simpson's single-plane formula (A4C). ECG was performed in all patients during the follow-up. Standard blood samples were analysed for liver functions: aspartat-aminotranferase (AST), gama-glutamyl transferase (GMT), Quick-time in \%, for renal function: creatinine, for lipids (total cholesterol), HDL-subfraction, triacyglycerides (TAG). We took also parameters of height $(\mathrm{cm})$, weight $(\mathrm{kg})$ and blood pressure $(\mathrm{mm} / \mathrm{Hg})$ and heart rate (HR, beats per minute - BPM).

Heart failure was diagnosed by taking a history, physical examination, echocardiography and a good effect of treatment. Atrial fibrillation was diagnosed by taking a history, physical examination and confirmed by ECG. Any documented onset of rhythm disorder during the period of follow-up was considered as atrial fibrillation. Delirium was confirmed by a psychiatrist. Cerebral vascular accident (CVA) or transient ischemic attack (TIA) was confirmed by a neurologist. Hypertension (pressure over 140/90 mmHg measured repeatedly or taking antihypertensive drugs) and diabetes (hyperglycaemia - fasting glucose over $7.0 \mathrm{mmol} / \mathrm{L}$ measured minimally twice) were diagnosed by taking a history, used treatments and documentation.

\section{Statistical methods}

Data were analysed by the unpaired Student's t-test (twotail) for the assessment of the variance of particular variables and categorical binary data by the Pearson's chi-squared statistic test from a 2-by-2 table. The results were given as the mean $\pm \mathrm{SD}$. The data were processed by Excel and Gnumeric spreadsheets with a statistical supplement and R - an environment for statistical computing. The $\mathrm{p}$ value $<0.05$ was considered statistically significant. Biological dependencies were surveyed by a correlation analysis (simple linear regression) as the correlation coefficient (r) and the level of correlation was compared according to Cohen (1998) weak correlation $r\{0.1-0.299\}$, moderate correlation $r\{0.3-0.5\}$ and strong correlation $\mathrm{r}\{>0.5\}$ (21).

\section{Baseline characteristics of subjects}

Baseline description and characteristics of the whole cohort of 100 subjects divided by demographics, history of drinking, echocardiographic parameters (during enrolment) and biochemical analysis can be seen below (Tab. 1).

Baseline characteristics by risk factors in the whole cohort of participants (hypertension, smoking, diabetes) and cardiovascular diseases (nobody has established CHD, 1 subject had CVA/TIA in history) is noted in Table 2.

\section{Results}

I. Patients were divided into 2 subgroups - one group with the consumer's daily dose $\geq 120 \mathrm{~g}$ of ethanol per day and another with $\leq 120$ g per day to obtain valid data from 2 relatively homogenous groups of subjects - observing the relation between a daily dose and monitored parameters. Our assumption was based on a boundary dose of 120 grams due to the fact that this dose divided consumers into 2 homogenous subgroups (also considering a sta-

Tab. 1. Baseline characteristics of the subjects - the whole cohort.

\begin{tabular}{|c|c|c|}
\hline Parameter & Mean & $\mathrm{SD}$ \\
\hline \multicolumn{3}{|l|}{ Demographics $(\mathrm{n}=100)$} \\
\hline Age $[y]$ & 52.6 & 10.5 \\
\hline Height $[\mathrm{cm}]$ & 176.6 & 5.2 \\
\hline Weight [kg] & 81 & 13.7 \\
\hline Sex & 98 men 2 women & \\
\hline \multicolumn{3}{|l|}{ Drinking } \\
\hline History of drinking [y] & 28 & 13 \\
\hline CDD [grams/day] & 145 & 115 \\
\hline TTLD $[\mathrm{kg}]$ & 1348 & 1135 \\
\hline \multicolumn{3}{|l|}{ ECHOCG parameters } \\
\hline LVEDD [mm] & 54.2 & 7.4 \\
\hline $\mathrm{EF}[\%]$ & 48.2 & 10.7 \\
\hline $\mathrm{LA}[\mathrm{mm}]$ & 46.28 & 7.08 \\
\hline HR [beats per minute] & 97.4 & 24 \\
\hline \multicolumn{3}{|l|}{ Biochemical analysis } \\
\hline $\operatorname{AST}[\mu \mathrm{kat} / \mathrm{L}]$ & 1.243 & 1.101 \\
\hline $\mathrm{GMT}[\mu \mathrm{kat} / \mathrm{L}]$ & 2.663 & 2.426 \\
\hline Creatinine $[\mu \mathrm{mol} / \mathrm{L}]$ & 90.64 & 34.11 \\
\hline Quick $[\%]$ & 73.68 & 20.76 \\
\hline Cholesterole total $[\mathrm{mmol} / \mathrm{L}]$ & 4.68 & 1.33 \\
\hline Cholesterole-HDL [mmol/L] & 1.39 & 0.78 \\
\hline $\mathrm{TAG}[\mathrm{mmol} / \mathrm{L}]$ & 1.271 & 0.538 \\
\hline
\end{tabular}

LVEDD - lef ventricular enddiastolic diameter, EF - ejection fraction, LA - left atrium diameter from parasternal long axis, HR - heart rate, AST - aspartataminostransferase, GMT - gamaglutamyltranferase, HDL - high density lipoproteins, TAG triacylglyceroles

Tab. 2. Baseline characteristics - the whole cohort.

\begin{tabular}{lc}
\hline & Frequency n (\%) \\
\hline Risk factors & \\
Hypertension & $48(48)$ \\
Smoking & $63(63)$ \\
Diabetes mellitus & $10(10)$ \\
\hline Cardiovascular disease & $0(0)$ \\
History of CAD/IM & $1(1)$ \\
History of CVA/TIA &
\end{tabular}

CAD/IM - coronary artery disease/myocardial infarction, CVA/TIA - Cerebral vascular accident/transient ischaemic attack 
tistic parameter of SD). Characteristics of subjects by the amount of consumed alcohol are displayed in Table 3.

Between the groups, the following parameters were statistically different: in demographics - parameter age showed that heavier consumers over $120 \mathrm{~g}$ daily were a bit younger $(\mathrm{p}=0.01)$, with a higher weight $(\mathrm{p}=0.008)$ and also a higher height $(\mathrm{p}=0.0001)$, in parameters causing drinking - as expected CDD ( $p<0.0001)$, TTLD $(\mathrm{p}<0.0001)$, in history of drinking a small difference was found $(p=0.07)$ - heavier drinkers drank for a bit shorter period. There were no differences between the groups in the echo-parameters ejection fraction $\mathrm{EF}(\mathrm{p}=0.43)$, in the diameter of left atrium LA $(p=0.51)$. Left chamber - LVEDD - was slightly bigger (but not significantly) in the group with a heavier drinking pattern ( $p=0.09$ ). Sinilarly, the parameter of heart rate HR was not significantly different $(\mathrm{p}=0.43)$. This could be explained by the tendency to sinus tachycardia by a reduced vagal tone also in cases of the absence of atrial fibrillation in both groups of heavy drinkers. There were no differences in any biochemical parameters between the groups - as displayed in Table 3, except for AST, paradoxically the level of this enzyme was higher in the group of consumers below 120 grams/daily $(\mathrm{p}=0.03)$.

II: Data regarding the dose and duration of alcohol consumption were used for a regression analysis, which showed a low correlation and nonlinear character between the duration of alcohol consumption and monitored parameters. Therefore, it was advisable to search for a correlation between the daily or total cumulative dose of alcohol in the whole group. Such composed groups were retested by the Student's t-test focused on the relation between the cumulative daily dose of ethanol and parameters LVEDD, LVEF and LA diameter. A probability in the cor-
Tab. 4. Characteristics - Group 1 and 2.

\begin{tabular}{lccc}
\hline & $\begin{array}{c}\text { Group }<120 \\
\text { gr/d }\end{array}$ & $\begin{array}{c}\text { Group } \geq 120 \\
\text { gr/d }\end{array}$ & \multirow{2}{*}{ p value } \\
\cline { 2 - 3 } & \multicolumn{3}{c}{$\%$ of } \\
\hline Risk factors & 60.7 & 31.8 & 0.004 \\
$\quad$ Hypertension & 58.9 & 68.2 & 0.341 \\
Smoking & 7.1 & 13.6 & 0.283 \\
Diabetes mellitus & 50 & & \\
Cardiovascular event/disease & 33.3 & 23.5 & 0.652 \\
Episode of AFIP & 7.1 & 9.1 & 0.308 \\
Episode of heart failure & 2 & 0 & 0.722 \\
CVA/TIA & 29.2 & 35 & 0.559 \\
CAD/IM & & & \\
Delirium & & & \\
\hline
\end{tabular}

*)absolute number, not processed for a low rate

$\mathrm{CAD} / \mathrm{IM}$ - coronary artery disease/myocardial infarction, CVA/TIA - Cerebral vascular accident/transient ischaemic attack, AFIP - atrial fibrillation

relation between LVEDD/CDD was small $(r=0.180, \mathrm{p}=0.071)$, also in LVEDD/TTLD $(r=0.166, \mathrm{p}=0.0979)$ - small dependency according to Cohen. However, the duration of drinking was not dependent to LVEDD ( $\mathrm{r}=0.001, \mathrm{p}=0.9889$ ). In other parameters (EF, LA), there was no correlation - dependency not validated see the following: parameter $\mathrm{EF}$ : $\mathrm{EF} / \mathrm{CDD} \mathrm{r}=0.064(\mathrm{p}=0.5302)$, $\mathrm{EF} /$ Duration of drinking $\mathrm{r}=0.087(\mathrm{p}=0.3870), \mathrm{EF} / \mathrm{TTLD} \mathrm{r}=0.081$ $(\mathrm{p}=0.4203)$, parameter LA diameter: LA/CDD $\mathrm{r}=0.028(\mathrm{p}=0.7833)$, LA/duration of drinking $r=0.061(\mathrm{p}=0.5433), \mathrm{LA} / \mathrm{TTLD} \mathrm{r}=0.084$ $(\mathrm{p}=0.4057)$. The value of CDD seemed to be a more appropriate value than TTLD, because subjects were able to remember their daily drinking in a short history, not their TTLD in a long history.

III: When comparing these two groups of patients, the percentage of diabetes mellitus $(\mathrm{p}=0.283)$, episodes of heart failure

Tab. 3. Characteristics - Group 1 and 2.

\begin{tabular}{|c|c|c|c|c|c|}
\hline & \multicolumn{2}{|c|}{ Group 1 consumption $<120$ grams/day } & \multicolumn{2}{|c|}{ Group 2 consumption $\geq 120$ grams/day } & \multirow{2}{*}{$\mathrm{p}$ value } \\
\hline & Mean & SD & Mean & SD & \\
\hline \multicolumn{6}{|l|}{ Demographics } \\
\hline Age [y] & 55.00 & 9.66 & 49.55 & 10.78 & 0.0101 \\
\hline Weight $[\mathrm{kg}]$ & 77.29 & 11.78 & 85.94 & 14.63 & 0.0082 \\
\hline Height $[\mathrm{cm}]$ & 173.20 & 3.49 & 181.00 & 3.30 & 0.0001 \\
\hline \multicolumn{6}{|l|}{ Drinking } \\
\hline History of drinking [y] & 29 & 13 & 25 & 12 & 0.0731 \\
\hline CDD [grams/day] & 80.07 & 27.25 & 228.63 & 131.82 & $<0.0001$ \\
\hline TTLD $[\mathrm{kg}]$ & 852.00 & 487.62 & 1970.00 & 1407.19 & $<0.0001$ \\
\hline \multicolumn{6}{|l|}{ ECHOCG parameters } \\
\hline LVEDD [mm] & 53.09 & 6.35 & 55.64 & 8.38 & 0.0981 \\
\hline $\mathrm{EF}[\%]$ & 48.96 & 9.30 & 47.23 & 12.21 & 0.4367 \\
\hline $\mathrm{LA}[\mathrm{mm}]$ & 45.86 & 6.45 & 46.82 & 7.86 & 0.5138 \\
\hline HR [beats per minute] & 95 & 25.29 & 99 & 22.45 & 0.4338 \\
\hline \multicolumn{6}{|l|}{ Biochemical analysis } \\
\hline AST $[\mu \mathrm{kat} / \mathrm{L}]$ & 1.43 & 1.33 & 1.00 & 0.64 & 0.0376 \\
\hline GMT $[\mu \mathrm{kat} / \mathrm{L}]$ & 2.59 & 2.16 & 2.76 & 2.75 & 0.7324 \\
\hline Creatinine $[\mu \mathrm{mol} / \mathrm{L}]$ & 93.21 & 33.08 & 87.36 & 35.50 & 0.4016 \\
\hline Quick [\%] & 73.61 & 22.39 & 73.77 & 18.75 & 0.9679 \\
\hline Chol-total $[\mathrm{mmol} / \mathrm{L}]$ & 4.81 & 1.54 & 4.55 & 1.06 & 0.3501 \\
\hline Chol-HDL [mmol/L] & 1.36 & 0.88 & 1.44 & 0.66 & 0.7276 \\
\hline $\mathrm{TAG}[\mathrm{mmol} / \mathrm{L}]$ & 1.30 & 0.58 & 1.24 & 0.50 & 0.6699 \\
\hline
\end{tabular}

$\overline{\mathrm{CDD}}$ - cumulative daily dose of $100 \%$ ethanol, TTLD - total life dose of $100 \%$ ethanol, LVEDD - lef ventricular enddiastolic diameter, EF - ejection fraction, LA - left atrium diameter from parasternal long axis, HR - heart rate, AST - aspartataminostransferase, GMT - gamaglutamyltranferase, HDL - high density lipoproteins, Chol cholesterole, TAG - triacylglyceroles 
( $p=0.308)$, atrial fibrillation $(\mathrm{p}=0.652), \mathrm{CVA} / \mathrm{TIA}(\mathrm{p}=0.722)$ and delirium $(\mathrm{p}=0.559)$ were not significantly different. The incidence of ischaemic strokes despite the absence of anticoagulant treatment was not different. No subject had any other documented rhythm disorder (e.g. flutter, or atrial tachycardia) except for atrial fibrillation what is consistent with Koskinen (22). When comparing the aspect of hypertension - there was a difference $(\mathrm{p}=0.004)$ - more events in the lower-consumption group (Tab. 4).

\section{Discussion}

Our data present that in the Liptov region, the consumption of alcohol is higher (more than 3 litres per year, attributable to a higher consumption of spirits, not wine or beer) than in the rest of Slovakia. Fauchier et al (28) had a similar group of alcohol consumers. He followed 134 patients (IDCM, ACMP), duration of follow-up was 51 months, 50 subjects were considered as heavy drinkers - but particular data in the specific subgroup of heavy drinkers were not available. Nicolas et al. (12) published data, where the term TTLD was used, but he stressed the difference between TTLD and CCD; not all binge-drinkers develop ACMP, daily intake is necessary. The same author (12) observed 60 subjects with a consumption over $100 \mathrm{~g}$ of ethanol daily for 10 years; in the period of 6 years there were $51 \%$ of subjects hospitalised for HF symptoms. In conformity with (13) and (14) we confirmed that the dependence of alcohol-related damage of the myocardium from CDD is absolutely nonlinear. Urbano-Marquez (15) displayed that in cases of symptomatic ACMP, the duration of alcohol intake was about 25 years, in asymptomatic cases 16 years. CDD was in symptomatic cases of ACMP about 280 grams of ethanol daily. Lazarevic et al (16) observed consumers over 90 $\mathrm{g} /$ daily - he divided them into 3 groups according to the length of consumption to 5, from 5-10 and over 10 years. The following information was revealed - dilation of left ventricle was a very early sign of ACMP and was followed by diastolic dysfunction/ impaired relaxation of ventricle - in conformity with our data from 2004 (6). In our group, the incidence of AFIP was $48 \%$, whereas Nicolas et al (12) describes $25 \%$. It is possible that a higher incidence of AFIP was caused by episodic/binge drinking of some subjects. That is conformed with (19); moreover, no association of alcohol consumption with a risk of death was found among the subjects with atrial fibrillation (20). Kloner and Rezkalla (9) and Castelnuovo (18) observed drinkers only with protective doses of alcohol (mild/moderate drinking; 1-7 drinks per week). In addition, the subjects changed their drinking habits (in contrast with our subjects), so no comparison could be achieved. Evaluation of the levels of HDL lipids seems to be questionable, because favourable effect of lipids HDL is blunted by a high consumption in both our groups. Moreover, the association between alcohol and HDL-C is modified by a genotype $(10,26)$. No subject in our survey had another documented rhythm disorder (e.g. flutter, or atrial tachycardia) than atrial fibrillation that was consistent with Koskinen (22). Heavy drinkers should have a higher blood pressure/incidence of hypertension in contrast with moderate drinkers $(7,17)$. This was not confirmed in our study. A bit higher rate of heart failure episodes was in the group with a lower alcohol consumption $<120$ $\mathrm{g}$ /day. It is likely due to more cases of hypertension. In accordance with Bryson`s data (26), alcohol consumption appears to have a more complex relationship with episodes of heart failure, there is no linear dependence. Nonetheless, a strong contribution of hypertension and atrial fibrillation as risk factors for strokes must be considered, especially in the background of heavy drinking $(23,27)$.

\section{Limitations}

Limitations of this study must be considered. Alcohol intake was self-reported, family-member confirmed, not all subjects were addressed by a short questionnaire (CAGE). We had incomplete information on the pattern drinking in all subjects in cohort and therefore we could not examine the potential effects of binge drinking $(11,12)$. The outcomes might also have been affected by a pattern of drinking. Another weakness of studies was the heterogeneity of the groups. In our study, there was the vast majority of men $(98 \%)$ and no clear suggestions about the situation in women. It is necessary to consider also changes in LVEDD, EF, valvular flows during a day period. Alcohol has different sudden, mid-time, total/long time effect, so in the context of CDD, the drinking pattern must be considered. The knowledge of delirium and also hypertension was only yes/no; no exact numbered values. The data about social status were not available, the data were in some cases unreliable and incomplete. Another limitation was the absence of appropriate comparison group, as we published previously (2004) (6). Underreporting by heavy drinkers is another possible source of bias (25). We have knowledge about a type of beverage (beer, wine, liquor), but due to small number groups computing valid data was impossible - although most evidence suggested beer and spirits, not wine. We did not evaluate any other medication (mainly in subjects with heart failure) except for antihypertensive drugs. Finally, 4 years is probably a too short period to collect morbidity/mortality data, the number of events may be too low to demonstrate differences between two groups. Last, but not least, we miss a large, multicentric study, in which one group are consumers, another group are abstainers - but there may be a lot of ethical, behavioral and logistic problems. Nevertheless, only this will give correct answers to all questions about drinking alcohol.

\section{Conclusion}

The fact, that alcohol consumers and abstainers are "echocardiographically different", was observed and published in our paper in 2008 (6). In our current 4-year study we present that according to statistics monitored echocardiograhic parameters (LVEF, LVEDD, LA) were not significantly $(\mathrm{p}<0.05)$ different between the group of alcohol consumers under $120 \mathrm{~g}$ and over $120 \mathrm{~g}$ per day. As another result in our prospective 4-year follow-up study of alcohol consumers, we found out the fact that when comparing both groups of patients according to CDD, the percentage of $\mathrm{HF}$ episodes was not significantly different ( 33 vs $24 \%, \mathrm{p}=0.308$ ), similarly, the incidence of delirium ( 29 vs $35 \%, \mathrm{p}=0.559$ ). The percentage of AFiP episodes was paradoxically higher in the group 
with the lower consumption ( 50 vs $45.5 \%, \mathrm{p}=0.652$ ), which, however, did not cause a higher incidence of ischemic strokes between the groups $(\mathrm{p}=0.722)$ despite the absence of anticoagulant treatment. Notably, $8 \%$ of subjects died, by contrast, not due to $\mathrm{CV}$ reasons (2 sudden deaths, not excluded fatal arrhythmia), but mostly of cirrhosis/bleeding.

Furthermore, we found out also the following interesting fact: only $2 \%$ of the followed-up subjects suffered from a non-fatal myocardial infarction (MI) during the observation - both cases of MI were in the group with the lower alcohol consumption $<120 \mathrm{~g} /$ day. No cardiac ischemic events were observed in the high intake group. These results suggested that the protective alcohol effect for ischemic cardiac event is present not only in a weak protective drinking (24), but also in heavy drinking.

\section{References}

1. Piano Marian R. Alcohol and Heart Failure. J Cardiac Failure 2002; 8 (4): 239-244.

2. Constanzo S, Castelnuovo A. Alcohol consumption and mortality in patients with cardiovascular disease. J Am Coll Cardiol 2010; 55 (13): 1339-1346.

3. Kyčina P, Murin J. Alkoholová kardiomyopatia - má miesto aj v súčasnej psychiatrii? Alkoholizmus a drogové závislosti 2011; 46 (5).

4. Heretik a spol. EPIAF - Epidemiológia alkoholizmu a fajčenia na Slovensku. Psychoprof, Nové Zámky, 2008, s. 152.

5. Novotný V, Heretik A et al. Epidemiológia alkoholizmu vo svete a na Slovensku. Lek Obzor 2010; 41 (3): 103.

6. Kyčina P. Alkoholová kardiomyopatia - stanovenie vybraných funkčných a morfologických parametrov srdca echokardiograficky vzhl'adom ku kvantite, kvalite a dobe konzumu alkoholu. Cor Vasa 2008; 50 (Suppl 7-8).

7. Piano Marian R. Alcoholic Cardiomyopathy: Incidence, Clinical Characteristics and Pathophysiology. Chest 2002; 121: 1638-1650.

8. Fauchier L. Alcoholic cardiomyopathy and ventricular arrhythmias. Chest 2003; 120: 1320

9. Kloner R, Rezkalla S. To drink or not to drink? That is the question. Circulation 2007; 116: 1306-1317.

10. Jensen M, Mukamal K, Overvard K. Alcohol consumption, TaqIB polymorphism of cholesterol ester transfer protein, high-density lipoprotein cholesterol and risk of coronary heart disease in men and women. Eur Heart J 2008; 29: 104-112.

11. Ellison R. Importance of pattern of alcohol consumption. Circulation 2005; 112: 3818-3819.
12. Nicolas JM, Fernandez-Solá J, Estruch R, Paré JC, Sacanella E, Urbano-Márquez A, Rubin E. The effect of controlled drinking in alcoholic cardiomyopathy. Ann Intern Med 2002; 136: 192-200.

13. Mathews EC, Gradin JM, Henry WL. Echocardiographic abnormalities in chronic alcoholics with and without overt congestive heart failure. Am J Cardiol 1981; 47: 570-578.

14. Kupari M, Koskinen P, Suokas A. Left ventricular filling impairment in asymptomatic chronic alcoholics. Am J Cardiol 1990; 66: 1473-1477.

15. Urbano-Márquez A, Estruch R, Navarro-Lopez F. The Effects of alcoholism on skeletal and cardiac muscle. N Engl J Med 1989; 320: 409-145.

16. Lazarevic AM, Natakani S, Neskovic AN. Early changes in left ventricular function in chronic asymptomatic alcoholics: relation to the duration of heavy drinking. J Am Coll Cardiol 2000; 35: 1599-1606.

17. Moshmoush B, Abi-Mansour P. Alcohol and the Heart. Archives of Internal Medicine 1991; 151 (1): 36-40.

18. Constanzo S, Castelnuovo A. Cardiovascular and overall mortality risk in relation to alcohol consumption in patients with cardiovascular disease. Circulation 2010; 121: 1951-1959.

19. Conen D, Tedrow UB. Alcohol consumption and risk of incident atrial fibrillation in women. JAMA; 2008: 300: 2489-2496.

20. Mukamal KJ, Psaty BM. Alcohol consumption and risk and prognosis of atrial fibrillation among older adults: the Cardiovascular health study. Amer Heart J 2007; 153: 260-266.

21. Cohen J. Statistical power analysis for the behavioral sciences (2nd ed), 1988, Lawrence Erlbaum Associates, Inc., ISBN: 0-8058-0283-5.

22. Koskinen P, Kupari M. Alcohol consumption of patients with supraventricular tachyarrhythmias other than atrial fibrillation. Alcohol 1991; 26: 199-206.

23. Mukamal K, Chen Ch, Rao S. Alcohol consumption and cardiovascular mortality among U.S. adults 1987-2002. J Amer Coll Cardiol 2010; 55 (13): 1328-1335.

24. Janszky I, Ljung R, Ahnve S. Alcohol and long-term prognosis after a first acute myocardial infarction: the SHEEP study. Eur Heart J 2008; 29: 45-53.

25. Klatsky A. Alcohol and cardiovascular mortality. J Amer Coll Cardiol 2010; 55 (13): 1336-1338.

26. Bryson L, Mukamal K, Mittleman M. The association of alcohol consumption and incident heart failure. J Amer Coll Cardiol 2006; 48: 305-311.

27. Constant J. The alcoholic cardiomyopathies - Genuine and pseudo. Cardiology 1999; 91: 92-95.

28. Fauchier L, Babuty D. Comparison of long-term outcome of alcoholic and idiopathic dilated cardiomyopathy. Eur Heart J 2000; 21: 306-314.

Received April 11, 2012. Accepted January 27, 2013. 